\title{
Reviewing of metalloporphyrins as novel catalysts for synthesis of conducting and water-soluble polymers
}

\author{
Zahra Zamiraei ${ }^{a} *$, Maryam Golzar ${ }^{b}$, Hoda Hamidi ${ }^{\text {iD }}$ c \\ a Environmental Research Institute, Academic Center for Education, Culture \& Research (ACECR), \\ 4144635699, Rasht, Iran \\ ${ }^{\mathrm{b}}$ Department of Chemistry, university campus2, university of Guilan, Rasht,Iran \\ ${ }^{\mathrm{c}}$ Department of Chemistry, Payame Noor University (PNU), P. O. Box, 19395-3697 Tehran, Iran \\ * Corresponding author's E-mail address: Zamiraei@ gmail.com, Tel.: +989038954754
}

Received: 14 October 2018, Revised: 25 October 2018, Accepted: 18 November 2018

\begin{abstract}
A B S T R A C T
Porphyrins are a group of heterocyclic macrocycle organic compounds, composed of four modified pyrrole subunits interconnected at their $\alpha$ carbon atoms via methine bridges $(=\mathrm{CH}-$ ). Porphyrins have attracted much attention because of their unique structures and a wide spectrum of very useful physicochemical and biological properties, such as anion binding, stabilization of metal ions with unusual oxidation states, electron transfer, and construction of peculiar supramolecular assemblies. The synthesis of electroactive and water-soluble polymers were accomplished with water-soluble metal (III) porphyrins in the presence of a template. The polymerization by matelloporphyrin is simple (one-step), chemically mild, and environmentally benign and requires minimal separation. This approach provides a distinct advantage over similar reactions employing native enzymes due to higher stability and lower price of the catalysts.
\end{abstract}

Keywords: Matelloporphyrin, Conducting polymer, water-soluble polymer, Oxidative polymerization.

\section{G R A P H I C A L A B S T RACT}

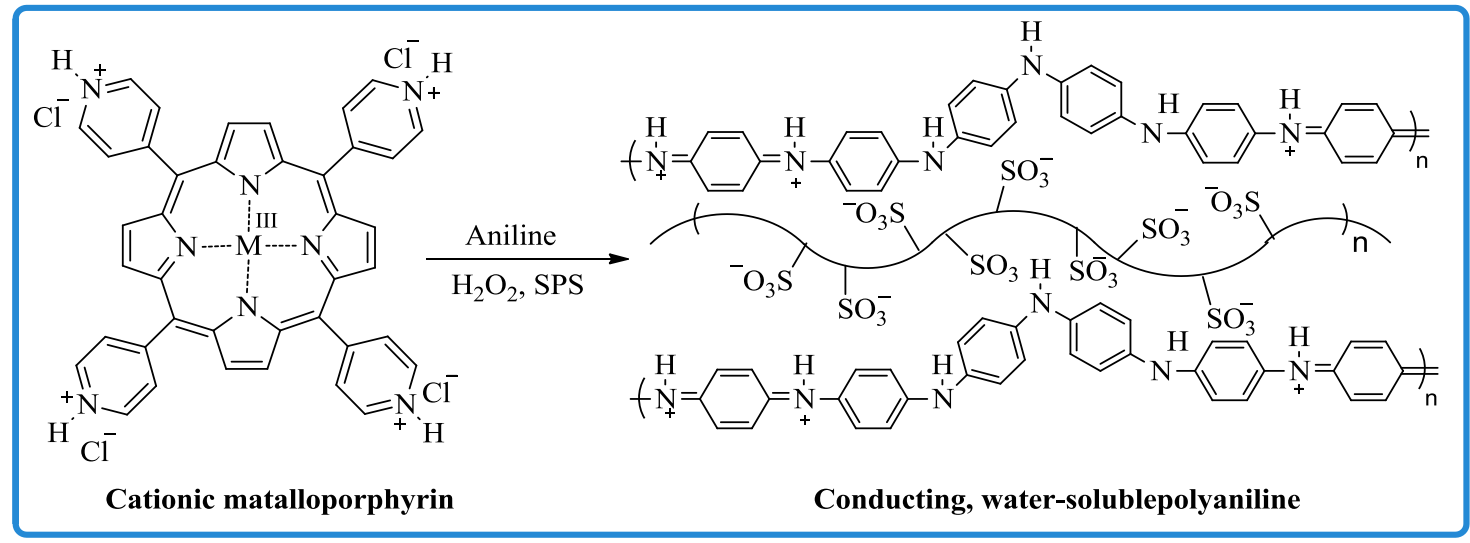




\section{Introduction}

Porphyrins are a group of heterocyclic macrocycle organic compounds, composed of four modified pyrrole subunits interconnected at their $\alpha$ carbon atoms via methine bridges $(=\mathrm{CH}-)$. The parent porphyrin is porphine, a rare chemical compound of exclusively theoretical interest. Substituted porphines are called porphyrins. With a total of $22 \pi$-electrons, of which $18 \pi$-electrons form a planar, continuous cycle, the porphyrin ring structure is often described as aromatic (Figure 1) [1]. One result of the large conjugated system is that porphyrins typically absorb strongly in the visible region of the electromagnetic spectrum, i.e., they are deeply colored. The name "porphyrin" derives from the Greek word porphyra, meaning purple [2].

Porphyrins have attracted much attention because of their unique structures and a wide spectrum of very useful physicochemical and biological properties, such as anion binding, stabilization of metal ions with unusual oxidation states, electron transfer, and construction of peculiar supramolecular assemblies [3].

Metal complexes derived from porphyrins occur naturally. One of the best-known families of porphyrin complexes is heme, the pigment in red blood cells, a cofactor of the protein hemoglobin [4].

The metalloporphyrins have been widely used in catalytic oxidation reactions with oxidants such as hydrogen peroxide [5]. Furthermore, metalloporphyrins have a structure similar to the active site of the enzyme, and have the advantages of being cheap and more stable [6].

In recent decades the field of conducting polymers has attracted much attention from many scientists due to their interesting optical and electrical properties. Since their discovery in 1977, they have been investigated for many technological applications, such as organic lightweight batteries, microelectronics, optical displays, antistatic coatings, sensors, microwave absorption and electromagnetic shielding [7-11]. Also, transition-metal complexes are known for their catalytic activities in many polymerization reactions $[12,13]$. These complexes can be successfully used as effective catalysts to control the radical polymerization of monomers [14, 15].

The general structure of anionic (a) and cationic (b) water-soluble porphyrins are shown in Figure 2.

The synthesis of electroactive polymers were accomplished with water-soluble metal (III) porphyrins in the presence of a template. 

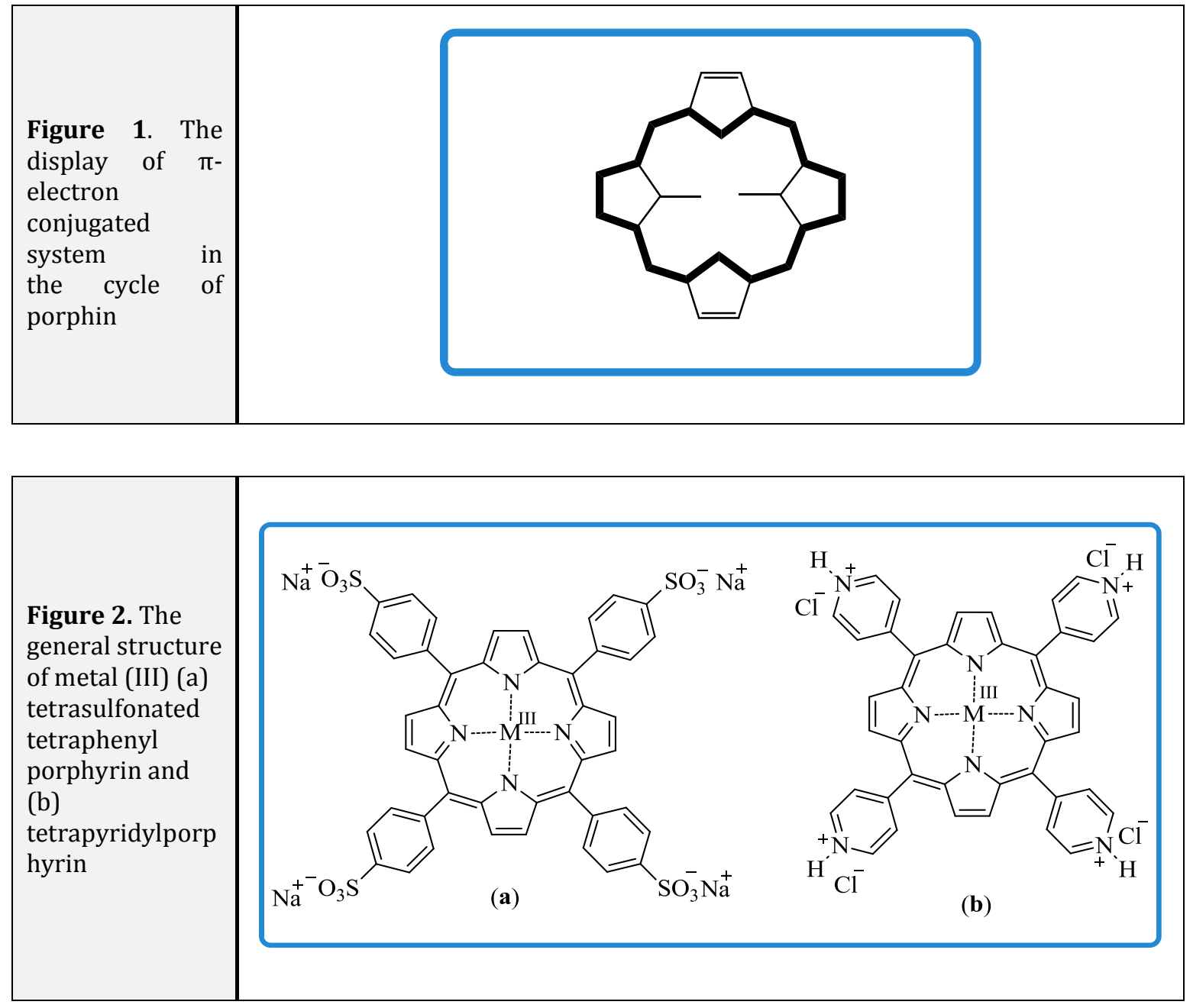

\section{Anionic water-soluble porphyrins}

\subsection{Synthesis of Conducting Water-}

Soluble Polyaniline with Anionic Iron

(III) Porphyrin

The development of new efficient catalysts has an important role in polymer research. Aniline and its derivatives have also been shown to polymerize via an enzymatic oxidation process [16].

HRP and related enzymes show low stability under non physiological conditions, and they are relatively expensive.

Water-soluble metalloporphyrins mimic the various reactions of HRP and other monooxygenases in different reactions. It was reported a novel route for the polymerization of aniline with hydrogen peroxide catalyzed by anionic, watersoluble iron (III) tetra(psulfonatophenyl)porphyrin ( $\mathrm{Fe}_{\text {III }}$ TPPS) [17]. The polymerization was carried out under pH 2 in the presence of sulfonated polystyrene (SPS) as a template. The 
synthesized polymer was a water-soluble, electroactive, and conducting PANI/SPS complex. The progress of the reactions was monitored spectroscopically.

A scheme of PANI synthesized in the presence of SPS is shown in Figure 3, where SPS acts as the template. The SPS (1) provides a preferential local environment that facilitates the para-directed coupling of the monomer, (2) provides counterions for doping, and (3) maintains the water solubility for synthesized PANI.

The proposed mechanism for the formation of a reactive intermediate in the polymerization of aniline with FeTPPS is shown in Figure 4. On the basis of the literature reports $[18,19]$, the oxoiron (IV) radical cation is responsible for initiating the formation of the aniline cation radical, which attacks the other aniline molecule to form a dimer, and hence the reaction further propagates to give PANI.

\subsection{Synthesis of water-soluble conducting polypyrrole with anionic porphyrins}

Of the many conducting properties identified so far, polypyrrole (PPy) and its derivatives have been studied extensively because of its many interesting properties such as good conductivity, and high stability in oxidized form.

Polymers based on pyrrole, currently used for organic batteries and display devices are also of great interest [30, 31]. Chemical and electrochemical polymerizations of pyrrole result in insoluble form of PPy.

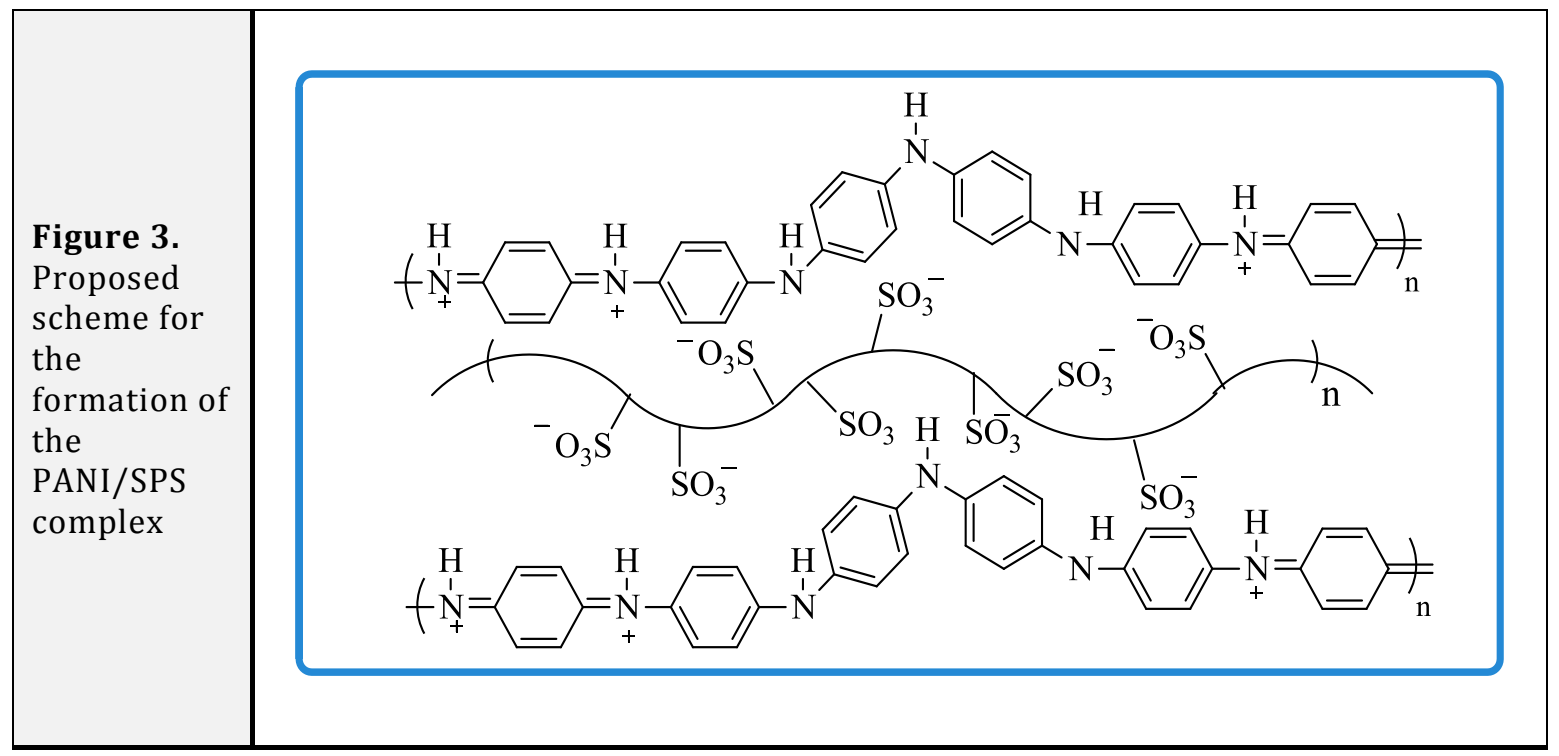




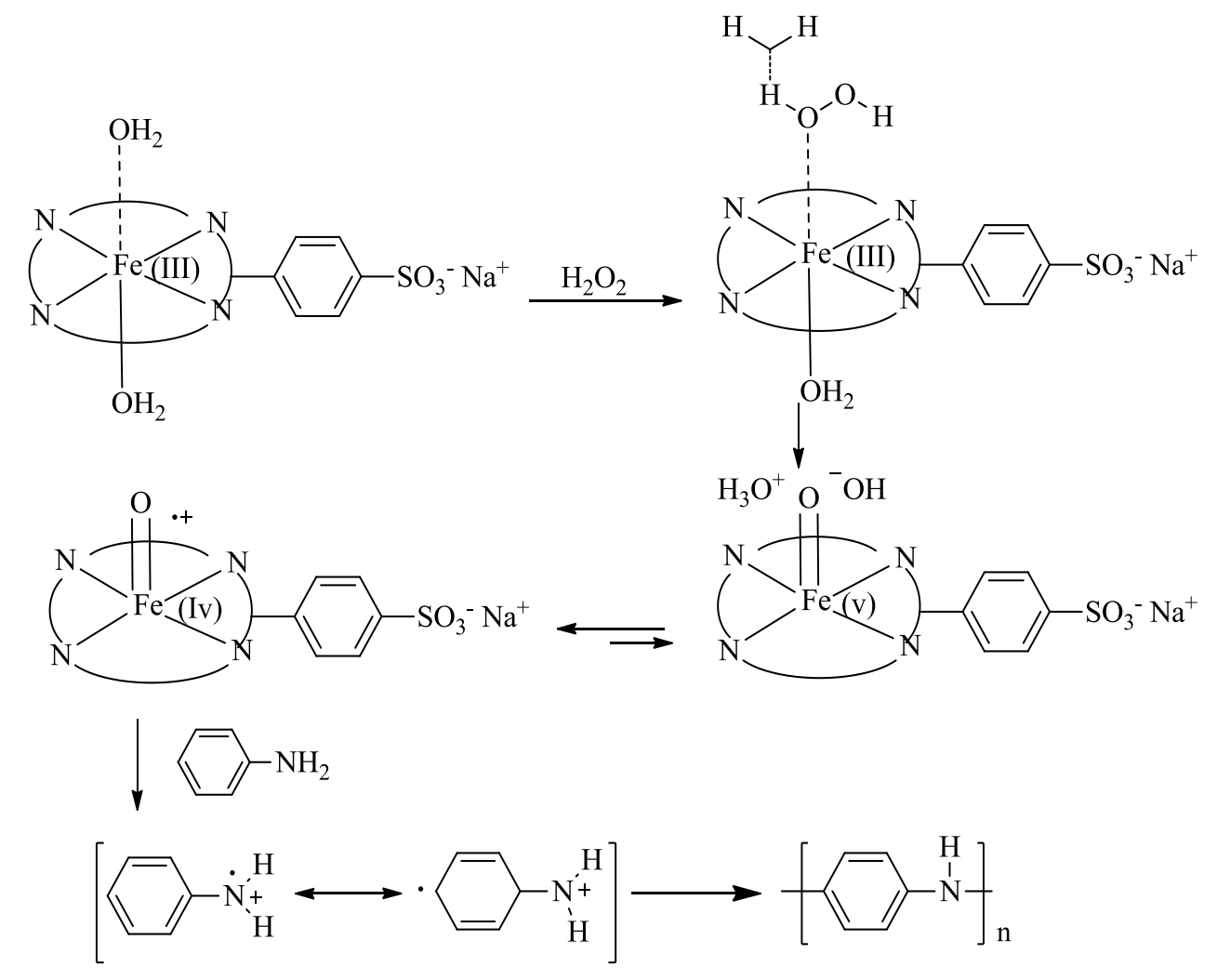

Figure 4. Proposed mechanism for the polymerization of aniline with FeTPPS

Encouraged by a variety of reports based on the processability and effectiveness of water-soluble polymers, a novel synthesis method of water-soluble PPy is reported by using iron (III) tetra(psulfonatophenyl)porphyrin (Fe $\left.{ }_{\text {III }} \mathrm{TSPP}\right)$, Cobalt(III) tetra(psulfonatophenyl)porphyrin (CoIIITSPP) and manganese(III) tetra(psulfonatophenyl)porphyrin (MnIIITSPP) as effective catalysts in the presence of sulfonated polystyrene (SPS) as a template [32].
The IR spectrum of PPy/SPS complexes measured in transmission mode are shown in Figure 8. FT-IR spectroscopy indicates that these complexes are oxidized structures with covalently bonded oxygen, which differs from native PPy that was synthesized under oxygenfree conditions previously [33]. The absorption peak, observed as a broad band at $3300 \mathrm{~cm}^{-1}$, is assigned to $\mathrm{O}-\mathrm{H}$ stretching vibration. The peak at 1710 $\mathrm{cm}^{-1}$ is believed to be due to the carbonyl group. Another feature in the FT-IR 
spectra is the skeletal stretching of the pyrrole ring, which occurs in the 1550 $\mathrm{cm}^{-1}$ region [34]. While the PPy was doped by a certain anion the N-H band of the pyrrole ring was not observed in the FT-IR spectrum (in $3400 \mathrm{~cm}^{-1}$ ) [35]. Also, the peaks observed at 1008 and $1036 \mathrm{~cm}^{-}$
1, corresponded to symmetric and asymmetric $S=0$ stretching and a band at $670 \mathrm{~cm}^{-1}$ which was attributed to the SO3 group confirmed the presence of SPS in the complex. These data indicate that the polymer consists of carbonyl and hydroxyl groups.
Figure 8. FT-IR spectra of PPy/SPS complexes synthesized by (a) Fe ${ }^{\text {IIITSPP, (b) Mn }}{ }^{\text {IIITSPP }}$ and (c) Co ${ }^{\text {IIITSPP }}$ catalysts

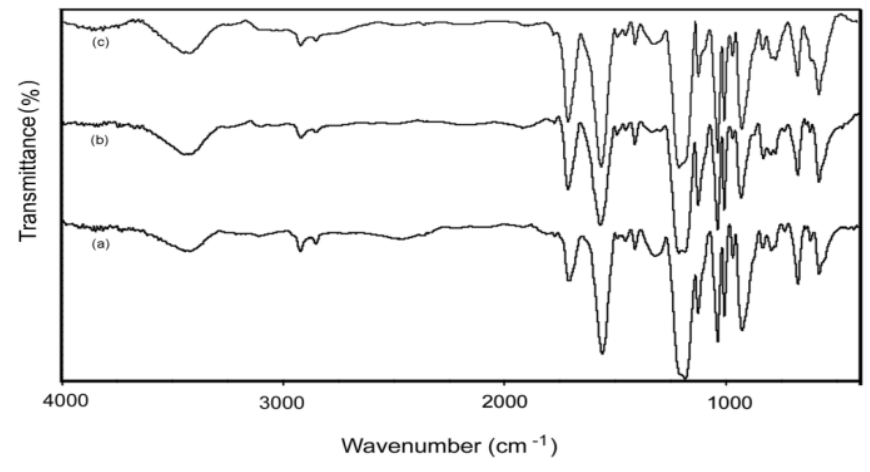

\section{Cationic water-soluble polyaniline}

\subsection{Cationic metalloporphyrins for} synthesis of conducting, water-soluble polyaniline

The unique oxidative approach has been developed which addresses and resolves current limitations of both the enzymatic and the chemical polymerization of aniline.

It is reported the polymerization of aniline with hydrogen peroxide catalyzed by cationic water-soluble iron (III) tetrapyridylporphyrin [ $\left.\mathrm{Fe}_{\text {III }}(\mathrm{TPyP})\right]$, manganese (III) tetrapyridyl porphyrin [MnIII (TPyP)] and cobalt (III) tetrapyridyl porphyrin [CoIII (TPyP)] in aqueous solutions [20]. This method, which is simple and environmentally benign, consists of using anionic polymeric template (SPS) to promote the head-to-tail coupling of aniline radicals.

This results in obtaining a water-soluble complex of electrically conducting PANI [20]. The synthesized polymer was confirmed by UV-vis, FT-IR spectroscopy and cyclic voltammetry (CV). Table 1 shows the comparison of UV-vis absorption and cyclic voltammograms of this polymer 
when synthesized by cationic metalloporphyrins, anionic metalloporphyrins (FeTSPP) [17] and metallophthalocyanine (FeTSPc) [22] in Table 1.

The polymerization of aniline by metalloporphyrine in aqueous solution at $\mathrm{pH} 2$ and in the presence of a strong polyelectrolyte, SPS (poly (sodium 4styrene sulphonate)), produced the watersoluble and conducting form of polyaniline. As is shown in Figure 5 [17], after the addition of hydrogen peroxide to the solution of FeTPyP, iron (III) hydrogen peroxide porphyrin complex [(TPyP)FeIII$\mathrm{OOH}]$ was formed.

This is due to the fact that the Fe(TPyP)Cl complex tends to form a high-valent iron

(IV) oxo porphyrin cation radical intermediate [(TPyP) + Fe@0], via 0-0 bond heterolysis in the reaction between iron porphyrin complex with $\mathrm{H}_{2} \mathrm{O}_{2}$ [23-25].

Then, the intermediate reacts with aniline, resulting in the aniline cation radical. This cation radical attacks other cation radicals of the monomer to form a dimer, by eliminating two hydrogens. The reaction further propagates to give PANI [21]. The comparison of cationic and anionic porphyrins shows that higher polymerization yield is obtained when the cationic ones are used (results are shown in Table 1)

\subsection{Synthesis of water-soluble poly(catechol) catalyzed by cationic Iron (III) porphyrin}

The enormous interest in recent years for intensive research in the field of phenols and aromatic amine-based polymers is due to their wide applications [26]. These polymers have received considerable attention in industry and are employed for many purposes such as in adhesives, composites, and other applications [27].

Table 1. Comparison of UV-vis and CV data for PANI synthesized by cationic and anionic porphyrin and phthalocyanine catalysts

\begin{tabular}{|c|c|c|c|c|c|}
\hline \multirow[t]{2}{*}{ Catalyst } & \multicolumn{3}{|c|}{ Anodic peak ( $\mathrm{V}$ versus $\mathrm{Ag} / \mathrm{AgCl}$ ) } & \multirow{2}{*}{$\begin{array}{l}\text { Anodic peak } \\
\text { current }(\mu \mathrm{A})\end{array}$} & \multirow{2}{*}{$\begin{array}{l}\text { UV-vis absorbance } \\
\text { (about } 750 \mathrm{~nm} \text { ) }\end{array}$} \\
\hline & Epa1 & Epa2 & Epa3 & & \\
\hline FeTPyP & 0.47 & - & - & 200 & 1.7 \\
\hline FeTSPP & 0.5 & - & - & 30 & 1.6 \\
\hline FeTSPc & 0.27 & 0.57 & 0.80 & 110 & 1.3 \\
\hline
\end{tabular}




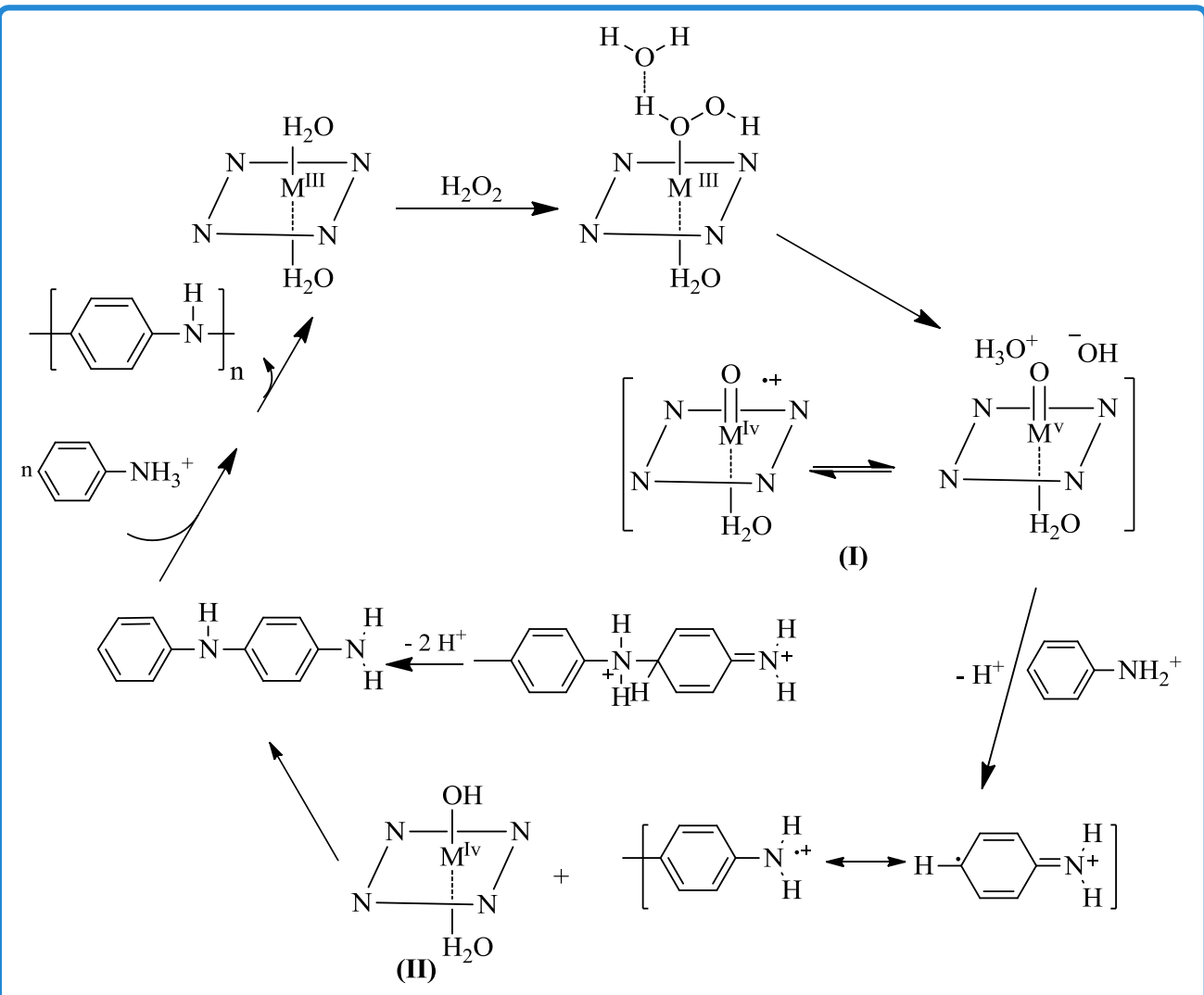

Figure 5. Proposed mechanism for the polymerization of aniline with cationic metalloporphyrins (M $=\mathrm{Fe}, \mathrm{Mn}$, and $\mathrm{Co}$ )

Poly(catechol) with free hydroxyl groups have potent for applications in the immobilization of some species. The control of properties is difficult in oxidative coupling reactions that are carried out at extreme temperatures, pressures, and pHs employing inorganic catalysts [28].

The synthesis of poly(catechol) was carried out by cationic metalloporphyrin as a catalyst and hydrogen peroxide as an oxidant in the presence of SPS as a template in a mild conditions [29].

The mechanism of catechol polymerization by FeTPyP is shown in Figure 6.

Based on this mechanism, after the addition of hydrogen peroxide to the solution of FeTPyP, intermediate were formed. Then, the intermediate reacts with catechol, resulting in the catechol cation radical. This radical cation attacks other cation radicals of the monomer to 
form a dimmer, with elimination of two hydrogens. The reaction further propagates to give poly(catechol). Formation of poly(catechol) was characterized by both FT-IR and cyclic voltammetry. The results are compatible with poly(catechol) structure that shown in Figure 7.

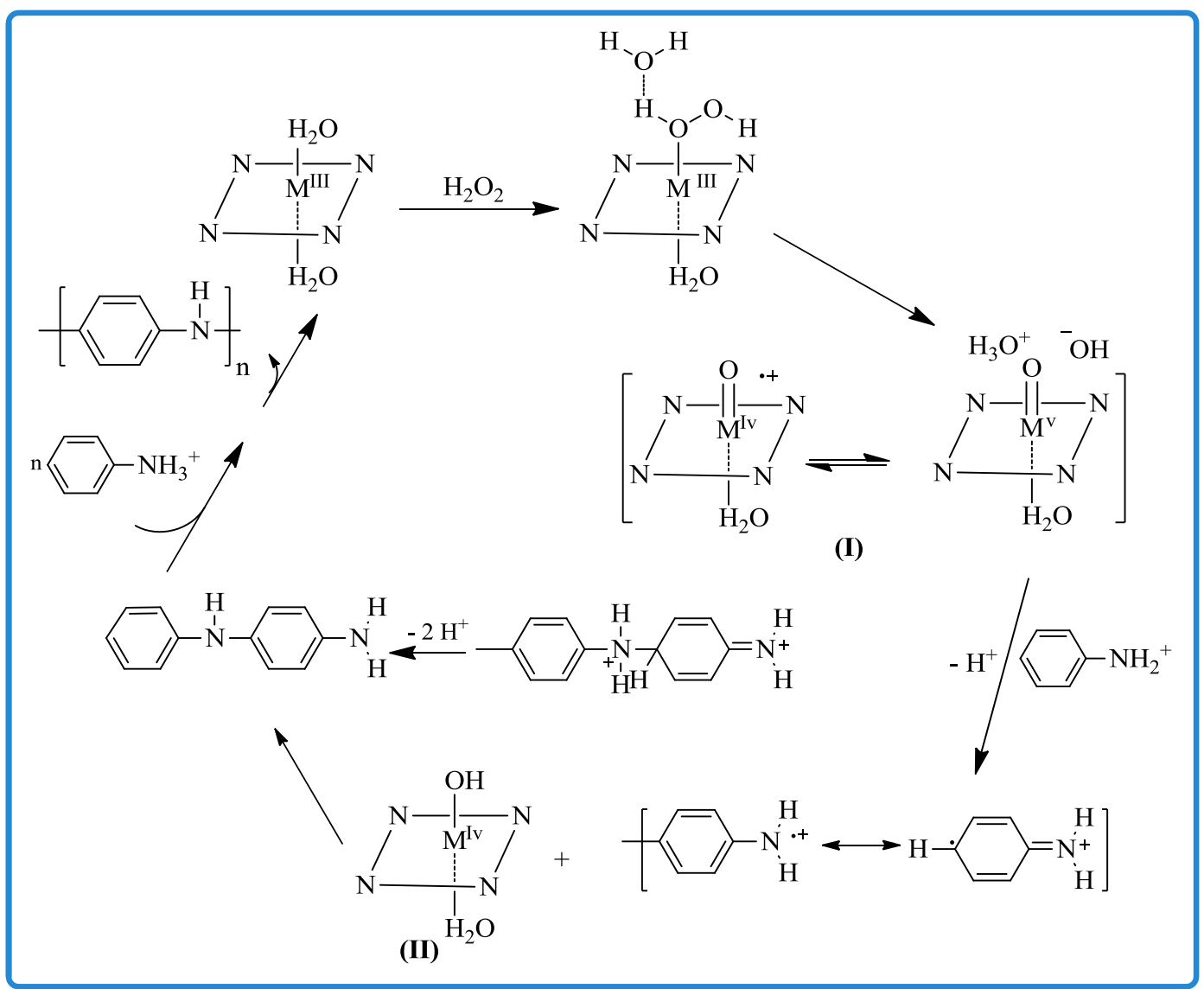

Figure 6. Proposed mechanism for the polymerization of catechol with cationic metalloporphyrin (FeTPyP)

Figure 7. The proposed chemical structure of porphyrin catalyzed poly(catechol)

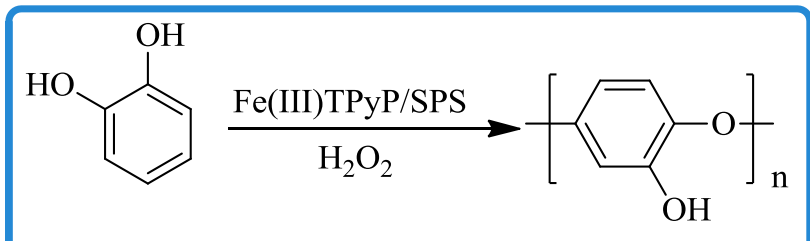




\section{Conclusion}

The synthesis of electroactive polymers were accomplished with water-soluble metal (III) porphyrins in the presence of a template. The robustness of the synthetic porphyrin catalyst was demonstrated by the ability of this catalyst to carry out the polymerization reaction at various conditions. Because of the slow demetallation of the catalyst under these conditions, polymerization was carried out in an aqueous acidic solution. This polymerization by matelloporphyrin is simple (one-step), chemically mild, and environmentally benign and requires

\section{References}

[1]. A.S. Ivanov, A.I. Boldyrev, Org. Biomol. Chem., 2014, 12, 6145-6150.

[2]. A. Goldberg, K.E.L. McColl, M.R. Moore, C. Rimington, Disorders of porphyrin metabolism. Springer Science \& Business Media, 2013.

[3]. T.D. Lash, J. Porphyrins Phthalocyanines, 2011, 15, 1093-1115.

[4]. S. Severance, I. Hamza, Chem. Rev., 2009, 109, 4596-4616.

[5]. J.T. Groves, Z. Gross, On the mechanism of epoxidation and hydroxylation catalyzed by iron porphyrins. Evidence for nonintersecting reaction pathway, in: D.P. Kessissoglon (Ed.), Bioinorganic minimal separation. This approach provides a distinct advantage over similar reactions employing native enzymes due to higher stability and lower price of the catalysts. The comparison of cationic and anionic porphyrins shows that the polymerization of aniline yield of the former is higher. TGA data shows that the thermal stability of synthesized polymers by porphyrin is more than HRP-catalyzed one. In conclusion, we have introduced a new, simple and economical method for the preparation of water-soluble conducting polymers by porphyrins.

Chemistry, Kluwer, The Netherlands, 1995, p. 39.

[6]. S. Kobayashi, H. Uyama, S. Kimura, Chem. Rev., 2001, 101, 3793-3818.

[7]. R. Nagarajan, S. Tripathy, J. Kumar, F.F. Bruno, L. Samuelson, Macromolecules, 2000, 33, 9542-9547.

[8]. W. Liu, J. Kumar, S. Tripathy, K.J. Senecal, L. Samuelson, J. Am. Chem. Soc. 1999, 121, 71-78.

[9]. D. Kincal, A. Kumar, A.D. Child, J.R. Reynolds, Synth. Met., 1998, 92, 53-56. [10]. H.H. Kuhn, A.D. Child, W.C. Kimbrell, Synth. Met. 1995, 71, 2139-2142.

[11]. A. Kaynak, Fibers Polym., 2001, 2, 171-177.

[12]. M. Sawamoto, M. Kamigaito, Trends Polym. Sci., 1996, 4, 371-377. 
[13]. V. Percec, B. Barboiu, H.J. Kim, J. Am.

Chem. Soc., 1998, 120, 305-316.

[14]. T. Nishikawa, T. Ando, M. Kamigaito,M. Sawamoto,

Macromolecules, 1997, 30, 2244-2248.

[15]. G. Moineau, C. Granel, Ph. Dubois, R.

Jerome, Ph. Teyssie, Macromolecules, 1998, 31, 542-544.

[16]. D. Ichinohe, T Muranaka, T Sasaki, M Kobayashi, H. Kise, J PolymSci Part A: PolymChem, 1998, 36, 2593-2600.

[17]. M.R. Nabid, R. Sedghi, P.R. Jamaat, N. Safari, A. A. Entezami, J. Appl. Polym. Sci., 2006, 102, 2929-2934.

[18]. J.T. Groves, T.E. Nemo, J. Am. Chem. Soc., 1983, 105, 5786-5791.

[19]. J.T. Groves, Y. Watanabe, J. Am. Chem. Soc., 1988, 110, 8443-8452.

[20]. X. Hu, Y.Y. Zhang, K. Tang, G.L. Zou, Synth. Met., 2005, 150, 1-7.

[21]. X. Hu, K. Tang, S.G. Liu, Y.Y. Zhang, G.L. Zou, React. Funct. Polym., 2005, 65, 239-248.

[22]. M.R. Nabid, M. Shamsianpour, R. Sedghi, S. Osati, N. Safari, J. Porphyrins

Phthalocyanines, 2010, 14, 128-132.

[23]. P. Wang, J.S. Dordick, Macromolecules, 1998, 31, 941-943.

[24]. R. Premachandran, S. Banerjee, V.T. John, G.L. Mcpherson, J.A. Akkara, D.L. Kaplan, Chem. Mater., 1997, 9, 13421347.
[25]. K.S. Alva, J. Kumar, K.A. Marx, S.K. Tripathy, Macromolecules, 1997, 30, 4024-4029.

[26]. M.R. Nabid, Z. Zamiraei, R. Sedghi, N. Safari, Reactive and Functional Polymers, 2009, 69, 319-324.

[27]. V. Rumbau, R. Marcilla, E. Ochoteco, J.A. Pomposo, D. Mecerreyes, Macromolecules, 2006, 39, 8547-8549.

[28]. M.R. Nabid, R. Sedghi, P.R. Jamaat, N. Safari, A.A. Entezami, Appl. Catal. A: Gen., 2007, 328, 52-57.

[29]. Y.M. Goh, W. Nam, Inorg. Chem., 1999, 38, 914-920.

[30]. T.G. Traylor, C. Kim, W.P. Fann, C.L. Perrin, Tetrahedron, 1998, 54, 7977-7986.

[31]. T.J. McMurry, J.T. Groves, Metalloporphyrin models for cytochrome P-450, in: P.R. Ortiz de montellano (Ed.), Cytochrome P-450: Structure, Mechanism, and Biochemistry (B), Plenum, New York, 1986, p. 1.

[32]. P.W. Kopf, A.D. Little, Phenolic resin. In: Mark HF, Bikales NM, Overberger CG, Menges G (eds) Encyclopedia of polymer science and engineering. vol 11, 2nd edn. Wiley, New York, 1988, pp 45-95.

[33]. J.S. Dordick, M.A. Marletta, A.M. Klibanov, Biotechnol. Bioeng, 1987, 30, 3136.

[34]. J.A. Akkara, L.D. Kaplan, V.T. John, S.K. Tripathy, In: Salamone JC (ed) The 
polymeric materials encyclopedia, vol 3. [35]. M.R. Nabid, Z. Zamiraei, R. Sedghi, S. CRC Press, New York, 1996, pp 2116-2125. Nazari, Polymer bulletin, 2010, 64, 855-865. How to cite this manuscript: Zahra Zamiraei*, Maryam Golzar, Hoda Hamidi, Reviewing of metalloporphyrins as novel catalysts for synthesis of conducting and water-soluble polymers, $A d v$. J. Chem. A, 2018, 1(2), 105-115. 